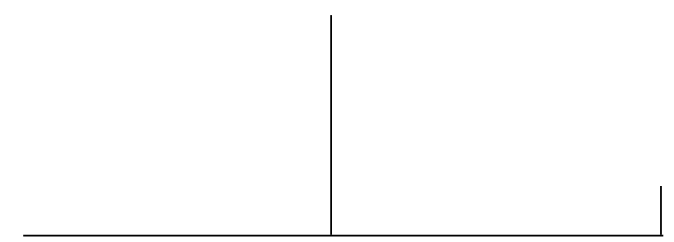

Rev. Latinoam. Psicopat. Fund., São Paulo, v. 13, n. 3, p. 469-481, setembro 2010

\title{
Avaliação e evidência clínica na saúde mental*
}

Carlo Viganò

\begin{abstract}
Este artigo apresenta o tema da "avaliação e evidência clínica" e sua relevância no atual cenário italiano da saúde mental. O tema é discutido a partir do método da "Construção do caso clínico" que vem sendo desenvolvido na Escola de Especialização em Psiquiatria da Universidade de Milão. A prática de apresentar e discutir os casos é um meio de avaliar a qualidade de uma equipe e de estimular a melhoria do serviço, sendo, ainda, um instrumento capaz de demonstrar que é possível uma avaliação que inclua a singularidade do sintoma como eixo da clínica.
\end{abstract}

Palavras-chave: Psicanálise, avaliação, caso clínico, saúde mental

* Publicado originalmente em Viganò, C. La costruzione del caso clínico. Frammenti, anno 14, n. 1, AUSL di Ravenna, 2005.

Tradução de Daniela Costa Bursztyn 


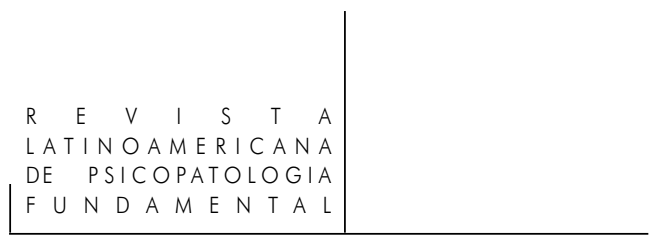

Esta contribuição nasce de uma longa experiência de "Construção do caso clínico" realizada na Escola de Especialização em Psiquiatria da Universidade de Milão, seguindo um modelo transferido mais tarde para diversas instituições psiquiátricas italianas (Ravenna, Macerata, Palermo). Hoje, a prática de apresentar e discutir os casos como meio de avaliar a qualidade de uma equipe e, ao mesmo tempo, como estímulo à melhoria do serviço é indicada como Audit* clínico. Nós a adaptamos à prática da saúde mental e a adotamos como instrumento (algoritmo) para tratar do tema da evidência clínica.

Pretendo expor um dado, extraído dessa experiência, capaz de esclarecer um erro de perspectiva muito frequente em nosso campo: considerar a psicanálise como um modelo de psicoterapia comparada às outras (sistêmica, cognitivo-comportamental, focal, estratégica etc.) através de métodos de verificação empírica ou de avaliação de eficácia que, em nome de um equivocado axioma científico, contradizem o mais elementar dos dados da sua experiência. Essa ideia da avaliação empírica de uma técnica psicoterápica parece responder a uma exigência de ocultar a real contribuição da psicanálise que é a de dar contribuições essenciais a cada axioma de avaliação clínica.

Da parte do campo médico vem uma indicação que segue uma lógica totalmente diversa daquela em voga hoje na avaliação para o campo da saúde mental. Refiro-me à corrente da EBM (Evidence Based Medicine) que promove a ideia de verificar as intervenções a partir de uma objetivação instrumental do quadro clínico, considerando a evidência como critério de leitura dos êxitos do mesmo quadro. A interrogação que lançamos é a seguinte: por que no campo da saúde mental não utilizar a lógica e a topologia como instrumento para construir a evidência clínica de um tratamento?

* O autor utiliza o termo médico de língua inglesa Audit para designar a exposição e a discussão de casos clínicos. (N. da T.) 


\section{SAÚDE MENTAL}

Trataria somente de uma extensão da proposta do "passe" àquele que conduz o tratamento, ou seja, a extensão do testemunho de um tratamento. O problema está no crédito acordado na escritura do caso como construção do objeto psíquico, ${ }^{1}$ do quanto vai além do dito do paciente e que o analista relança com seu ato. A evidência vem da resposta do paciente. O escrito que o Audit produz poderia construir a conexão, a passagem exata do que se compreende no tratamento ao que disto se pode ler na avaliação.

A evidência clínica é um critério mais manejável e aderente à operação do tratamento que se quer testar. Não é um simulacro de procedimento "científico" onde o valor de diagnóstico e, sobretudo, de cura (operações de sentido não quantificáveis) são tomados de modo arbitrário, tendo como única mensuração a estatística. Como nunca esteve claro para todos, é preciso interrogar que esse procedimento se limite em contabilizar quais operações seriam mais frequentes entre outras operações codificadas, sem entrar no interior da indústria do tratamento e de sua eficácia.

Não resta dúvida que as diversas formas e escansões temporais da posição subjetiva na relação com o trabalho de transferência, e não somente os efeitos terapêuticos da psicanálise, podem entrar na realização de um Audit. Mas isto deve ocorrer de modo adequado: não em uma competição (nem de compreensão, nem de explicação) com outras leituras, mas como estruturas reais do caso clínico e da lógica de suas respostas. Em outros termos, a contingência dessas estruturas é ligada ao caso clínico e não à teoria, enquanto o confronto (o seu valor universal) é garantido pela escritura e pela discussão dos casos.

\section{A evidência clínica}

Hoje o psicanalista tornou-se sensível ao tema da avaliação porque a exigência social de calcular o custo econômico das terapias, o que sempre existiu, começa a atingir também a sua prática. $O$ conflito se manifesta imediatamente porque as instituições que devem programar as intervenções continuaram a pensar a atribuição dos custos segundo a lógica desenvolvida historicamente na organização dos tratamentos hospitalares.

Na base dessa lógica estão os DRG (Diagnostic Rating Group) em que os diagnósticos são reagrupados em classes, correspondendo a uma tarifa para o

1. Referência ao texto freudiano "Construções em análise" de 1937.

Rev. Latinoam. Psicopat. Fund., São Paulo, v. 13, n. 3, p. 469-481, setembro 2010 


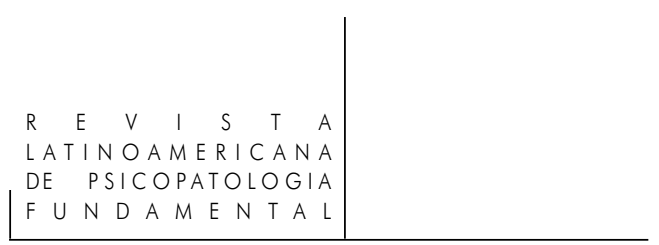

reembolso. O pressuposto deste cálculo é que um determinado diagnóstico corresponda a um protocolo de tratamento homogêneo e previsível. No interior desta lógica, a clínica é colocada em jogo somente para produzir o resultado da cura do sintoma ou de sua contenção com o menor dispêndio de dinheiro e de tempo. Este modelo perde o valor preditivo real quando a definição do sintoma e da sua modificação ou estabilização entram na competência clínica do caso a caso. O problema colocado para a saúde mental é este: se omitido o tempo lógico da transformação do problema psicológico como uma evidência clínica, essa transformação deixa de ser um dado determinante para o cálculo. Este cálculo, por sua vez, perde cada ancoragem real e torna-se ideológico ou, ainda, conflituoso.

Com essa dificuldade estão se deparando os projetos de reforma da saúde mental como aquele em curso na França ou aquele proposto na Itália por Burani e Procaccini. Esses projetos, pelo que eu saiba, ainda estão fechados na ideia de pedir à "ciência médica" a definição inicial da doença para, em seguida, proceder segundo a lógica acima mencionada. Diferindo da mais avançada reflexão da medicina, surge uma indicação de sinal distinto da evidência clínica tal como a psicanálise lacaniana, através de sua orientação lógico-estrutural, é capaz de fornecer um grande suporte metodológico, considerando as diferenças técnico-operativas de cada operador* ou dos grupos.

Encontro uma confirmação desse raciocínio a partir de uma decisão tomada recentemente pelo governo central da Suíça. Após uma ampla discussão sobre o sistema de reembolso da Casse ** - doenças no campo da saúde mental, o governo concluiu sobre a insuficiência do valor preditivo do sistema DRG (em torno de 8\%) e passou a recomendar uma forma de captação dos recursos para projetos individualizados. ${ }^{2}$ É nesse nível que a psicanálise entra em jogo com seu específico suporte aos países que mais sentem a influência do trio inicial: Freud, Jung e Bleuler e não como, ao contrário, gostariam os seus críticos no estabelecimento de protocolo de tratamento.

Para esclarecer, reagrupamos em três tempos lógicos os componentes do processo de acompanhamento na saúde mental conforme é possível formalizar,

* O termo operatori é característico da reforma psiquiátrica italiana e designa a função dos profissionais inseridos nos serviços de saúde mental. (N. da T.)

** Sigla referente ao sistema público de asseguração de doenças. (N. da T.)

2. Em outro trabalho demonstrei como esse vício ideológico no cálculo de custos para a saúde mental comporta um duplo dano: os desperdícios de recurso financeiro e da capacidade de estabilização oferecida pelo sintoma psicótico. Em outros termos, a ideologia da cura produz uma "nova cronicidade" caracterizada pela repetição cíclica das crises.

Rev. Latinoam. Psicopat. Fund., São Paulo, v. 13, n. 3, p. 469-481, setembro 2010 


\section{SAÚDE MENTAL}

aplicando a clínica lacaniana. É importante ressaltar que se trata de três grupos de operações, não necessariamente ordenados em um único protocolo operativo. A comparação pode ser feita com os três tempos da clínica clássica: anamnese, diagnóstico e terapia. O projeto concreto não pode desconsiderar a exaustão desses tempos lógicos, mesmo se forem contemplados em modos e tempos particulares em cada caso.

1) Um instante de ver: é o olhar clínico, a operação que isola a forma clínica. É o filtro que estabelece a "evidência" e coincide, cada vez menos, com o clássico diagnóstico categorial. Este último começa a se expandir rapidamente por privilegiar a categoria sociológica de "distúrbio", diferenciando-se da evidência clínica que inclui o tratamento e, portanto, a contingência clínica.

Mesmo a quantificação epidemiológica na lógica da avaliação deverá levar em conta os elementos que numa dada população e numa dada cultura resultam em "evidência". O caso da terapia obrigatória deve conservar o seu valor de exceção, confirmando a mesma regra. Nessa perspectiva, um indício da necessidade de inverter essa tendência foi dado pela Comissão que redige o DSM e que vem estudando, há mais de dois anos, um novo manual de tipo "dimensional" com objetivo de publicá-lo em 2007.* No entanto, devemos acrescentar, desde já, que nem mesmo o recurso da dimensão psicopatológica será suficiente para introduzir a evidência que permanece ancorada ao caso.

Este não é um tempo de mensurações, mas de avaliação. E permite avaliar quais seriam os dados adequados a sobrepor o tempo sucessivo da mensuração. Discutiremos, mais adiante, o quanto deste instante de ver seria oportuno conceder ao empírico.

2) Um tempo para compreender é o que hoje vem sendo comprimido e aspirado pelo tempo lógico sucessivo. É o tempo da avaliação da transferência e da formulação de um projeto de tratamento que coincide com o critério diagnóstico. Nesse ponto, a perversão lógica tende a se insinuar ao negligenciar esse tempo para dar precedência ao tratamento da urgência. É a mesma perversão da política que negligencia a "manutenção" porque deve se ocupar da queda dos custos. O argumento que faz calar cada discussão possível é: "Não temos dinheiro, devemos cortar as despesas". Chega-se ao absurdo de cortar pela raiz o que não custa nada, como o voluntariado, a escuta clínica, isto que o sujeito está disposto a pagar com sua pessoa. Deste modo, se endossa a ideia de que cada distúrbio corresponda biunivocamente a um capítulo de custos. É neste tempo que a mensuração desempenha sua função com a advertência de que não se trata

* Referência ao DSM-V, ainda não publicado. (N. da T.)

Rev. Latinoam. Psicopat. Fund., São Paulo, v. 13, n. 3, p. 469-481, setembro 2010 


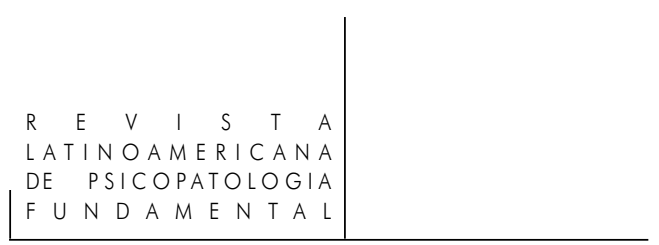

somente de mensuração financeira, mas, sobretudo, de medidas políticas, de prudência ou de prevenção.

3) O momento de concluir, como eu disse, é o que hoje tende a agir ao inverso: em vez de ser um ato político capaz de criar o espaço para o analítico ou terapêutico, torna-se manobra eleitoral, teatro para conquistar os votos das "reformas" crônicas (também cíclicas ou bipolares). Na medida em que não é estabelecido um critério no tempo anterior, será a utilidade imediata a decidir. Mesmo sendo este o tempo lógico em que, frequentemente, pode se manifestar o ódio pela psicanálise, não podemos pensar em contrastá-lo somente opondo-o ao ato analítico que se encontraria, sem bases reais, em uma contraposição ideológica.

Devemos encontrar todos os aliados possíveis no propósito de construir a dignidade ética e cultural do ato analítico.

\section{O mensurável e o não mensurável}

Em cada escolha humana há um cálculo ${ }^{3}$ e é por isso que cálculo e sujeito devem andar juntos. Devemos acrescentar que no cálculo há algo que é mensurável e algo que não é; e, por isso, uma escolha nunca é sem sujeito. Na clínica mais do que de empiria se deve falar de pragmática; onde se encontram os dados do cálculo, a contingência ligada ao fato que é o sujeito o objeto a calcular e, enfim, o desejo de quem calcula.

Freud era um entusiasta da ciência na época em que a ciência era ainda ligada a uma forte ideia de causa, como causa natural e, portanto, calculável em termos matemáticos. Lacan, por sua vez, não renunciando à pesquisa de uma forma científica para a subjetividade (matema) - a qual corresponde à invenção do passe para a avaliação do psicanalista -, vive no sulco da ciência relativista. Não todo o real é matemático e mensurável; é a ciência que traça as fronteiras do real que não é mais natural, mas o que permanece para além do simbólico e do mensurável. O tema da saúde mental coloca-se dentro destas novas fronteiras do real.

A saúde mental se impõe como problema quando não é mais a homeostase natural e biológica do vivente a definir o estado de saúde, mas uma quota de gozo do corpo que é própria de cada sujeito; não mais o silêncio dos órgãos, mas a sua palavra. Até o ponto que exista quem propôs definir a normalidade como patologia

3. Referência ao debate realizado com L.Brusa na Sessão Clínica de Milão em junho de 2004.

Rev. Latinoam. Psicopat. Fund., São Paulo, v. 13, n. 3, p. 469-481, setembro 2010 


\section{SAÚDE MENTAL}

que convém, que satisfaz um determinado sujeito, desorientando definitivamente a mensuração estatística (cf. Canguilhem, 1966) desta relação.

A ciência contemporânea constrói as evidências que têm valor de certeza no interior do quadro axiomático que as produziu. Dentro dessa perspectiva, Lacan lança uma diferença: ele não necessita encobrir com um valor universal as certezas que acrescenta. É suficiente dar um estatuto rigoroso e transmissível à estrutura subjetiva e à operação analítica.

O final de uma análise não é outra coisa senão a fórmula que contém os significantes fundamentais da história do sujeito, podendo ser material de um cálculo. É um cálculo útil, mesmo não tendo um valor universal, no momento em que se negligencia um elemento que é de uma ordem diferente daquela das ciências naturais: o objeto, que é particular de um sujeito e que condensa em si a marca incomensurável do gozo de sua existência. É o mesmo argumento que vale para a ciência biológica ${ }^{4}$ e, mais ainda, para psicologia e sociologia onde a certeza pode estar relacionada à avaliação de um fenômeno e ao cálculo de suas transformações, mas não chega a ter um valor preditivo no que diz respeito às variáveis subjetivas (gozo) que formam o mesmo fenômeno.

Com a avaliação a ordem da ciência passa à ordem da empiria, da perícia que consiste em dar um parecer utilizando a competência científica. Recolhem-se os dados e, em seguida, surge o problema de como agregá-los considerando as hipóteses e as teorias que não são internas às disciplinas "científicas" da psicologia, da sociologia, da biologia ou da psicanálise. A avaliação produz, por si mesma, o quadro axiomático. Deve-se realizar uma operação inversa àquela da ciência: recolher as evidências que as várias disciplinas são capazes de produzir, dando-lhes um quadro axiomático que sirva ao cálculo avaliativo. É sobre este ponto que as práticas de avaliação correntes vêm sendo discutidas.

De um modo geral, pode-se dizer que essas avaliações foram importadas acriticamente de algumas disciplinas particulares, dando-lhes um valor universal inapropriado e qualificado como científico. Misturam-se diferentes quadros axiomáticos, de tipo sociológico (estudo por classes homogêneas) com os

4. Ver conceito de plasticidade in F. Ansermet e P. Magistretti, 2006, p. 92-98. 
modelos de farmacologia clínica (estudo de duplo cego) e, de um modo geral, o processo dedutivo que deveria conduzir a axiomática avaliativa é substituído pelo cálculo estatístico.

Elementos que são heterogêneos e, portanto, incomensuráveis (como, por exemplo, o emprego de fármacos psicotrópicos, as terapias cognitivo-comportamentais, a psicanálise aplicada, o psicodrama etc.) recebem arbitrariamente a atribuição de um índice numérico para tornar possível um cálculo estatístico. Este será um cálculo que eliminará cada referência ao real, tornando-se uma anticiência.

Um exemplo disto é extraído de uma pesquisa que compara a eficácia de um fármaco com a de uma psicoterapia, utilizando o método do duplo cego. Dois grupos de sujeitos tornados equivalentes pela atribuição de um mesmo índice diagnóstico são mensurados segundo a escala numérica atribuída a este índice diagnóstico. Fora a insensatez clínica de privar os sujeitos de um ou de outro instrumento de tratamento, o fármaco ou a palavra, qualquer que fosse a avaliação com axiomas clínicos seriam capazes de fornecer uma riqueza de elementos avaliativos, nem sequer comparáveis, comprimindo os elementos de eventuais substituições do sintoma. Digamos que a pesquisa se relacione ao tom do humor no transtorno esquizoafetivo; qual lógica clínica nos dirá se uma variação de humor constitui uma melhoria da qualidade de vida do sujeito examinado? Um outro exemplo é retirado de um quesito que o mesmo laboratório farmacêutico propôs à nossa Unidade de Psiquiatria Integrada. A proposta surgiu da observação que um novo neuroléptico: quando se demonstrava particularmente eficaz em suspender a atividade delirante, notava-se sensivelmente o aumento à passagem ao ato suicida.

Seguir o caminho inverso daquele da ciência, tanto no tratamento quanto na sua avaliação, como mostrou Freud, significa renunciar realisticamente à ilusão de tornar tudo possível, como gostaria a atribuição imaginária dos números, para circunscrever o real, o impossível de medir, seguindo uma outra estrada: a do sujeito e da sua posição na demanda.

Paradoxalmente, a "falsa ciência" da estatística acaba atribuindo todo o peso da decisão ao fator subjetivo, a um desejo que não quer considerar a desordem. Pode-se dizer que haveria uma relação direta entre a falsa modéstia científica da disciplina de base e a sua influência no movimento avaliativo, ao ponto de invalidá-lo completamente.

Provavelmente na base desta aliança perversa está aquela que Michel Foucault chamava "biopolítica", ou seja, a que insere a vida e seus mecanismos no campo dos cálculos difíceis e que faz do poder-saber um agente de transformação da vida humana. Com isto, porém, pode-se sair do tema da avaliação e entrar em outro gênero de cálculo tipicamente contemporâneo: o da 


\section{SAÚDE MENTAL}

felicidade como direito social e valor absoluto. Aqui, no entanto, devemos nos fixar: se for decidido que tudo deve ser possível, então saberemos que está sendo empregado um uso cínico do cálculo, o da foraclusão do sujeito.

\section{Uma orientação analítica}

Podemos agora retomar o tempo lógico, retornando ao primeiro: somente no nível do sujeito é possível perceber o que hoje é irreconhecível no tema de avaliação. Os objetos oferecidos pelo mercado substituem um objeto, aquele que poderia mover a singularidade do desejo de um sujeito e que, por isso, é incomensurável. Como consequência, isto não torna eliminável um resíduo de incurável e interroga a economia de qualquer cálculo no âmbito da saúde mental diante da qual a sociedade não parece estar preparada. Por isso as pessoas veem com bons olhos o desconhecimento deste objeto não mensurável e não reduzível a um bom funcionamento. É, no entanto, uma falta de reconhecimento que falsifica as avaliações e que domestica a pesquisa clínica.

Neste ponto surge a hostilidade pela psicanálise porque na sua experiência este elemento incomensurável é algo do que se pode falar. Enquanto aquilo de que não se pode falar reduz o sintoma à pura disfunção ou distúrbio, a palavra - neste nível se coloca o problema da avaliação - pode permanecer como pura consolação e entretenimento. Uma primeira tarefa para a psicanálise é a de escutar isto que trabalha contra o ideal enunciado, a exigência unívoca da mensuração que leva ao silêncio. É a de manter legível isto que não é mensurável. De fato, algo deste ideal que, no entanto, vem do exterior, da massa, responde à natureza do sujeito enquanto dá um lugar ao significante mestre S1 que dá ao sujeito uma organização e, ao mesmo tempo, lhe faz obstáculo.

Com a análise, extraímos do sintoma esse algo como causa do desejo e através da ressonância da palavra encontramos no mensurável o não mensurável. Isto torna completamente diversa a operação do cálculo, porque faz do incurável algo fecundo. A prática lacaniana não visa o funcionamento de cada caso; assume a falha no seu centro e transforma a noção de êxito. É um modo de estabelecer uma relação com o real, com a insistência do impossível, pelo qual o fracasso torna-se somente um modo não subjetivado do sucesso. A presença do analista se coloca ao nível do equívoco da palavra para impedir que seja substituída pelo ideal da utilidade imediata (que está subordinada ao imperativo ditado do "direito à saúde"). Trata-se de salvaguardar as oscilações subjetivas ao nível do ideal "privado", criado pelo espelho do Outro (entre ideal e desejo) para que um ideal público não venha a desalojá-lo. Dito de outro modo, "A psicanálise... não tem 


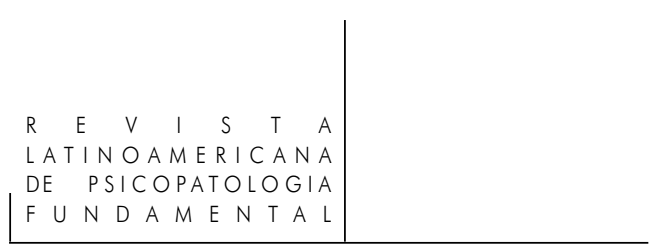

por objetivo eliminar os sintomas, senão uma vez estabelecida a função destes" (Laurent, s.d.).

Estes princípios da prática psicanalítica não podem ser reduzidos a questões técnicas internas ao tratamento, pois concernem à estrutura do sujeito e, portanto, isto deve ser levado em conta no nível de uma axiomática da avaliação. Existem alguns "dados" que podem tornar-se patrimônio comum da saúde mental se mantida a ideia da utilidade enganchada ao real da experiência. Indicarei sinteticamente três deles que são correlatos entre si:

A normalidade não é outra coisa senão o sintoma uma vez elaborado pelo sujeito como medida da sua saúde.

O tratamento é transformação do sintoma que o reduz a agente do desejo: é o sujeito que trata de si mesmo.

Desta “desconstrução” é possível fazer uma construção transmissível.

\section{Uma nota sobre evidência}

A pesquisa da evidência nasce de uma exigência advertida na prática da medicina, o que estendo à prática da saúde mental: dispor a teoria e os protocolos que dela derivam sob a avaliação da clínica, isto é, do caso particular. Sem esta disciplina contínua, qualquer uma das duas práticas tende a transformar-se em uma ideologia onde o quadro nosográfico funciona como véu fantasmático do doente real, contingente.

Naturalmente, a evidência na EBM responde a uma axiomática diferente daquela que concerne à saúde mental. No primeiro caso, a axiomática é sempre do tipo científica e a evidência é atribuída ao texto da mensuração instrumental; no segundo, o texto é o da construção do caso.

O texto da construção apresenta pontos de descontinuidade e de escansões que podemos ler como evidência clínica a partir de buracos e saltos lógicos que a pesquisa da análise estrutural permitiu localizar como produções subjetivas ( sintoma analítico). Nesse ponto a evidência intervém no sentido etimológico (exemplo, vídeo, como reforço para ver), mas não no sentido de uma interpretação que poderá ser feita por um operador (dando valor de supervisão ao trabalho de discussão do caso). O francês nos oferece uma homofonia interessante para esta operação de evidência: evider (perfurar), furar a imagem produzida na narração do caso em um ponto de indício onde se apresenta a transferência (outro matema fornecido pela análise). São estas perfurações produzidas no plano da imagem atual de um significante que age no après-coup. 


\section{SAÚDE MENTAL}

Como se pode ver bem, a pesquisa da evidência na saúde mental prevê como material o Audit clínico, mas também o algoritmo analítico para evidenciar o modo adequado sobre o texto do caso. Podemos dizer que a escritura do caso já utiliza alguns matemas analíticos como, por exemplo, o ponto de desencadeamento da angústia diferenciado da ansiedade generalizada ou do pânico. Há, portanto, uma formação do Audit clínico que exige a superação dos prejuízos ideológicos antipsicanalíticos. A evidência clínica vale para qualquer prática de tratamento com a condição de não tornar absoluta uma técnica, dando-lhe o valor de axioma. Somente assim será possível receber e aplicar o valor axiomático de algumas estruturas da subjetividade descoberta por Freud e Lacan.

Uma última consideração sobre evidência: esta é uma das figuras da antiga retórica (Cicerone e Quintiliano) que consistia em trazer o personagem ou uma situação de modo a suscitar a impressão de tê-los vivos diante dos olhos. É, portanto, a operação oposta àquela da "transparência" em que a visibilidade é ligada ao artifício (ideológico) de eliminar o tempo da vida. Entre essas duas existe a distância percorrida de um máximo de subjetivação à dessubjetivação. Isto representa um problema para EBM, pois valorização do dado contingente pode facilmente negligenciar a subjetividade do vivente para perseguir o imperativo de conservar em vida o organismo. É um problema da medicina especializada contemporânea e da sua prevalência científica, mas não há nenhuma razão no mundo para que este delicado problema venha a ser transferido para o campo da saúde mental. Dito de outro modo: quem procura as razões nessas especialidades foi buscá-las fora da ciência.

\section{Referências}

Ansermet, F.; Magistretti, P. Inconscio e plasticitá neuronale. La Psicoanalisi, Roma, n. 39, p. 92-98, 2006.

Canguilhem, G. Le normal et le pathologique. Paris: PUF, 1966.

Freud, S. (1937). Costruzione in analisi. In: Opere complete di Sigmund Freud. Torino: Boringhieri, 1984. v. XXIII.

LAURENT, E. Relieve anxiety? Mental online, n. 13, www.mental-nls.com.

Viganò, C. La costruzione del caso clínico. Frammenti, anno 14, n. 1, AUSL di Ravenna, 2005. 


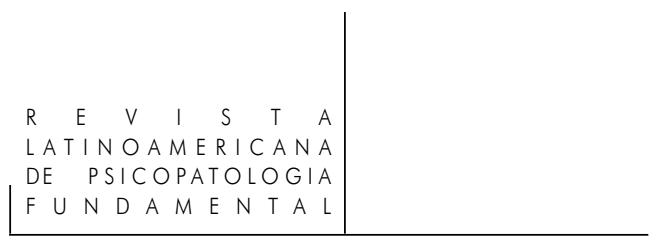

\section{Resumo}

(Evaluation and clinical evidence in mental health)

This paper is on the topic of "evaluation and clinical evidence" and its relevance to the Italian context of mental health services. The subject is discussed based on the method of "clinical case construction," which is being developed at the School of Specialization in Psychiatry of the University of Milan. The practice of presenting and discussing cases is a way of evaluating the quality of these services. It is also proof that an evaluation tool can be developed which includes the singularity of the symptom as the axis of clinical work.

Key words: Psychoanalysis, evaluation, clinical case, mental health

(Evaluation et évidence clinique en santé mentale)

Cet article introduit le thème de "l'évaluation et des evidences cliniques" et sa pertinence dans le contexte actuel de la santé mentale italienne. Le thème est discuté à partir de la méthode de "Construction de cas clinique" en cours d'élaboration dans l'École de Spécialisation en Psychiatrie de l'Université de Milan. La pratique de présenter et de discuter les cas est un moyen d'évaluer la qualité d'une équipe et stimuler l'amélioration du service et est également un outil pour démontrer qu'il est possible une évaluation qui comprend la singularité du symptôme comme l'axe de la clinique.

Mots clés: Psychanalyse, evaluation, cas clinique, santé mentale

(Evaluación y evidencia clínica en salud mental)

Este artículo introduce el tema de la "evaluación y las evidencias clínicas" y su relevancia en el escenario actual de la salud mental italiana. El tema se discute a partir del método de la "Construcción del caso clínico" que se está desarrollando en la Escuela de Especialización en Psiquiatría de la Universidad de Milán. La práctica de presentar y discutir los casos es un medio para evaluar la calidad de un equipo, estimular la mejora del servicio y también es una herramienta capaz de demostrar que es posible una evaluación que incluya la singularidad del síntoma como eje de la clínica.

Palabras claves: Psicoanálisis, evaluación, caso clínico, salud mental 


\section{SAÚDE MENTAL}

Citação/Citation: Viganò, C. Avaliação e evidência clínica na saúde mental. Revista Latinoamericana de Psicopatologia Fundamental, São Paulo, v. 13, n. 3, p. 469-481, set. 2010.

Editor do artigo/Editor: Profa. Dra. Ana Cristina Costa de Figueiredo

Recebido/Received: 15.5.2010/ 5.15.2010 Aceito/Accepted: 8.7.2010 / 7.8.2010

Copyright: @ 2009 Associação Universitária de Pesquisa em Psicopatologia Fundamental/ University Association for Research in Fundamental Psychopathology. Este é um artigo de livre acesso, que permite uso irrestrito, distribuição e reprodução em qualquer meio, desde que o autor e a fonte sejam citados/This is an open-access article, which permits unrestricted use, distribution, and reproduction in any medium, provided the original author and source are credited.

Financiamento/Funding: $\mathrm{O}$ autor declara não ter sido financiado ou apoiado/The author has no support or funding to report.

Conflito de interesses/Conflict of interest: $\mathrm{O}$ autor declara que não há conflito de interesses/The author declares that has no conflict of interest.

\section{Carlo Viganò}

Psiquiatra e psicanalista radicado em Milão, Itália; Membro da Scuola Lacaniana di Psicoanalisis (SLP) e da Ecole de la Cause Freudienne (ECF); Membro integrante da comissão de saúde mental da Associação Mundial de Psicanálise (AMP); Docente do Instituto Freudiano de Roma e do Centro Paul Lemoine di Palermo; Docente da Escola de Especialização em Psiquiatria da Università degli Studi di Milano/Consultor de Pesquisa junto à Cátedra de Psicoterapia da Universidade de Milão.

Via C. da Sesto 15

CAP 20123, Milano, Itália

e-mail: carlo.vigano@fastwebnet.it 